\title{
Pilot Performance With Predictive System Status Information
}

\author{
Anna C. Trujillo \\ NASA Langley Research Center \\ Hampton, VA 23681-0001
}

\begin{abstract}
Research has shown a strong pilot preference for predictive information of a ircraft system status in the flight deck. However, the benefits of predictive information have not been quantitatively demonstrated. The study described here attempted to identify and quantify these benefits if they existed. I n this smulator experiment, three types of predictive i nformation (none, whether a parameter was changing abnormally, and the time for a parameter to reach an alert range) and four initial times to an alert (1 minute, 5 minutes, 15 minutes, and ETA+45 minutes) were found to affect when subjects accomplished œrtain ations, such as accessing $\mathrm{p}$ ertinent checklists, declaing emergencies, diverting, and calling the fight attendant and dispatch.
\end{abstract}

\section{INTRODUCTION}

Much a necdotal evidence exists regarding the benefits predicting aircraft system fillures would bring to increasing the safety of flight. Documented instances exist where some type of early notification to the flight aew of a system parameter deviation could have prevented or lessened the consequences of an aircraft's system fillure [1], [2]. The benefits of predictive information, some have argued, are in the realm of improved decision making [3]-[5]. Thus, to describe and quantify the benefits of predictive information, a esearch program was undertaken to systematically explore these potential benefits.

Earlier research has shown a strong pilot preference for predictive information [6] and for certain types of predictive information, specifically, whether a system parameter (e.g., oil t emperature) was dhanging abnormally and the time remaining until that parameter reached a predefined value [7]. Pilots also indicated when they wanted to be told of a possible problem. For example, pilots only wanted to be notified that the parameter was moving if $\mathbf{i}$ would reach an alert range in less than 5 minutes; otherwise, they nould rather know the approximate time remaining until the alert [7].

\section{Objectives}

There w ere several objectives of this experiment. The primary objective was to identify the benefits of predictive information in an operational setting during non-normal system events. Benefits were defined a decision making pertaining to handling of the fault, which included aking actions to affect the onset of an alert, retrieving decklists, diverting a nd declaring emergencies, and workload associated $\mathrm{w}$ ith the non-normal system events. The secondary objective was to determine the most appropriate fom of predictive information and range of prediction times. Lastly, this experiment was conducted to corroborate previous research.

\section{Experimental Variables}

Of the $t$ hree experimental variables, two were directly manipulated: the predictive information available and the initial time to an alett. The predictive information available, a between subject variable, was one of three types: (1) none (baseline), (2) whether a parameter was increasing or decreasing abnormally (direction), or (3) the time to an dert (time). The initial time to an alert, a within subject variable, had four levels: (1) 1 minute, (2) 5 minutes, (3) 15 minutes, and (4) ETA+45 minutes (Estimated Time to Arrival). Baseline predictive information and ETA +45 minute initial time $t o$ an alert were control conditions. The third experimental variable, which was partially controlled in that the parameter would degrade in aregulated manner, was the four independent fults each subject encountered.

Predictive Information: In the baseline ondition, no predictive $\mathrm{i}$ nformation was available. Thus, when a parameter reached an alert range, the subjects saw the typical alert message (e.g., CABIN ALT) with the accompanying aural alert (table 1).

Table 1 -Examples of Predictive Information

\begin{tabular}{|l|l|l|}
\hline Condition & Predictive Information & Alert Information \\
\hline \hline Baseline & none & "CABIN ALT" \\
\hline Direction & "CABIN ALT INC" & "CABIN ALT" \\
\hline Time & "CABIN ALT 7MIN" & "CABIN ALT" \\
\hline
\end{tabular}

In the other two conditions, direction and time, subjects were notified that a parameter was moving bwards an alert range. In all cases, the predictive information presented to subjects was always correct and had an alert category of advisory. Furthermore, parameters increased or decreased at a constant rate dependent on the state of the aircraft. Lastly, when $t$ he parameter reached a alert range, the related standard aleit information message replaced the predictive information message (table 1).

For $\mathrm{t}$ he direction condition, subjects were told that a parameter was increasing or decreasing abnormally (table 1). For the time condition, subjects were told when a parameter would reach an alert range for the given aircraft state (table 1). The time to an alert was updated in increments of whole minutes if the time remaining was greater than 1 minute. If 
the time to an alert was less than 60 seconds, the message updated for every 15-second change in the time to an alert.

Initial Time to an Alert: Each subject saw four initial times to an dert (the time to an alert at the beginning of a failure): (1) 1 minute, (2) 5 minutes, (3) 15 minutes, and (4) E TA+45 minutes. The configuration of the aircraft affected the actual time to an alert; for example, throttling back the engine with the EGT (Exhaust Gas Temperature) increase would increase the time to an alert.

Faults: Each of the four data nuns, or scenarios, and the training run included afault in which a parameter would eventually reach an alert range if the subject look m action. The faults were (1) cabin altitude increase, (2) forward cargo overheat, (3) EGT increase, and (4) oil quantity decrease. The training run was an avionics overheat. All fillures were designed to behave as ealistically as possible [8]-[11] and are described below.

For the scenario with the cabin dtitude increase, the cabin altitude $\mathrm{i}$ ncreased to the airplane altitude. The outflow valve, if checked, was in the fully closed condition once the failure started. A lthough the increase could not be controlled $t$ hrough the environmental system, the cabin altitude $\mathrm{w}$ arning nould not be reached if the subject descended to no more than $10000 \mathrm{ft}$ and if he had at least 4 minutes until the alert range was to be reached-the time needed to descend from the initial altitude of $37000 \mathrm{ft}$ to $10000 \mathrm{ft}$.

In another data nu, the forward cargo hold, initially set-up for carrying animals, had a temperature increase until it reached the fre warning limit. If the subject hanged to the cargo mode, the temperature increase would slow. Also, if he discharged the forward cargo fre bottle before the alert range $w$ as reached, the forward cargo temperature would never reach the alert ange. If the subject discharged the forward c argo fire bottle after the fire warning, as the forward cargo fire checklist instructs him to do, the temperature would drop below the alert range.

During the scenario with the EGT increase, the BGT rose steadily and if it reached the alert ange, the subject would have to follow the engine failure/shutdown procedure. The increase could be slowed if the subject throttled back the engine with the increasing BGT or stopped if the affected engine was shut down. If the subject estarted the engine, the EGT would again increase until it reached the alert range.

The scenario with the al quantity decrease also involved an oil pressure decrease because of the bss of oil. The oil pressure triggered the alert once it eached an alert range. The only way to decrease the rate of al loss was to shut down the affected engine.

For $t$ he avionics overheat training nu, the rate of temperature increase could be decreased by changing the avionics mode $t \mathrm{o}$ override from its initial position of nomal. Furthermore, $\mathrm{b}$ y disconnecting bus 3 , the temperature would stay below the warning limit. Thus, the load on bus 3 was the primary cause of the overheat.

\section{EXPERIMENT DESIGN}

Subjects

Twelve glass-cockpit airline pilots familiar with ETOPS (Extended Twin engine OPerationS) rules participated as subjects. S even were aurrently first officers with the remaining five captains. The average age was 48 years old and the average commercial airline flight experience was 16 years.

\section{Test Design}

The experiment was run in the Advanced Civil Transport Simulator at the NASA Langley Research Center. This simulator had flight performance characteristics similar to a Boeing 757. The flight deck resembled a Boeing 747-400 or MD-11. The subject acted a captain, pilot-not-flying. A confederate first officer $(\mathrm{F} / \mathrm{O})$ was pilot-flying and he was well versed in the operation of the simulator. A confederate air traffic controller (ATC) and company dispatch operator provided the necessary coordination with the ground.

The flight was from Dulles arport to Charles de Gualle aiport with a 60-minute ETOPS nule; ie., the plane was never more than 60 minutes fom an alternate airfield. The 60-minute rule was used in order to have several PETs (Point of Equal Time); i.e., the point where the plane was 60 minutes f rom any suitable alternate airport. The scenarios w ere set-up such that ach segment of flight started before a PET; thus, this experiment only included the cruise phase of flight. If the configuration of the aircraft did $n$ ot change during the fault, the affected parameter would reach an alert range a few minutes before the aircraft intersected the PET excpt in the ETA +45 minute condition.

Any $m$ aterials and infomation the subject reeded were provided to him. Plotting charts, landing plates, a dspatch weather briefing, and a flight plan were available in paper form. Checklists were dectronic and mimicked the Boeing model o f the quick reference handbook [12]. Voice communication was used for ATC and dispatch. Both ATC and dispatch were able to s upply aurrent weather information at any of the diversion airfields. Basically, the weather at a 11 diversion aiffields was acceptable for landing-drizde $w$ ith a ceiling around $1000 \mathrm{f} \mathrm{t}$ and visibility approximately $1_{\text {_ }}$ miles with winds at no more than 10 knots. ATC also reasonably expedited any requests subjects had regarding course changes. The confederate F/O was able to answer operational questions from the subject; i.e., he supplied all the operational infomation nomally found in the aircraft manual. Lastly, subjects made any passenger announcements or held conferences with the head flight atendant, or purser, to the experimenter sitting in the back of the simulator.

As mentioned earlier, the faults and initial times to an dert were $w$ ithin-subject variables while the predictive information was between subjects. Since subjects could only see each failure once, each subject had four data runs in addition to a training nun. Thus, the overall results is that all subjects saw each of the four faults once and each of the four initial times to an alert once with one of the three types of predictive information. 


\section{Dependent Measures}

The dependent measures consisted of variables that defined whether the predictive information was beneficial: when and where certain actions occurred, and workload ratings, which were measured $u$ sing the NASA-TLX questionnaire on perceived workload [13]. Variables not directly dependent on a particular failure were when the subject turned offtrack, diverted to an ETOPS altemate airport, brought up the appropriate checklist, and initiated action pertaining to it; the time and space definition of the aircraft; and the workload ratings. Variables that were directly dependent on the failure involved actions the subject could take to affect the time to an alert, such $\mathbf{s}$ when an engine was shut down for the EGT increase scenario and the oil quantity decrease scenario.

\section{Procedure}

When a subject first arived, he received an overview on this experiment including i nstructions about the NASA-TLX questionnaire. After this introduction, the confederate $\mathrm{F} / \mathrm{O}$ gave a d etailed description of the simulator and its operation, and the flight plan to the subject before the training run started. The training mu included the avionics overheat fault 15 minutes into the flight. The time to an alert was 5 minutes given the initial aircraft configuration. No data were recorded during training.

A short break was taken after the training run and before data run 1. An hour lunch break fllowed the first data nun. After lunch, the subject completed data nuns 2 through 4. Each data run took approximately 30 minutes. At the end of each data run, the subject was asked about the failure, his actions, a nd his norkload. The presentation order of predictive i nformation and initial time to an alert were counterbalanced while scenario order was only partially balanced due to the number of subjects.

\section{Data Analysis}

For time data, a normalized time was calculated to extricate the fact that different initial times to an alert occurred during the flight. If the times were not normalized, the data clustered around bur dscrete categories dependent on the initial time to an alett. The nomalized time was

$$
\text { normalized time }=\frac{\text { time at which } X \text { occurred }}{\text { actual time to alert }}
$$

Times were taken fom filure start. The actual time to alert was when the alert truly occurred or nould have occured had the subject not done something to prevent it such as shut down an engine. These times were then analyzed using the general linear model in SPSS [14].

The specific actions analyzed were accessing the appropriate checklist, turning o ff path, diverting, declaring an emergency, checking the weather at the diversion airports, calling $t$ he fight attendant, and calling dspatch. Categorical data elated to these actions were analyzed with the i ndependent samples Chi-squared $\left(\chi^{2}\right)$ test in SPSS [14].

All failures had a checklist associated with them. Thus, if a parameter reached an alert, the subject should fllow the checklist. A subject could access the checklists before the alert range was reached if he so desired.

Under E TOPS rules, subjects had to divert for the oil quantity decrease and EGT increase failures when they shut down an engine. The ETOPS nules $d b$ not specify a diversion is necessary with cabin pressure loss, but for fiel efficiency reasons and passenger comfort, the logical choice would be to dvert. If a subject had a forward cargo fire waming, he would have to divert under ETOPS rules. If a subject discharged the fire bottle before the warning, thus preventing the temperature fom increasing into the dert range and averting a fire warning, he did mot technically have to divert but prudence recommended diverting anyhow because of the strong possibility of fre.

Three of the faults required subjects to descend: (1) the cabin altitude increase, and after engine shutdown for both (2) the EGT increase and (3) the oil quantity decrease. Also, checking weather a the diversion airport, telling the flight attendant what was happening and calling dispatch to let the company know the aurrent situation was not explicitly required $\mathrm{b}$ ut was considered good airmanship. Subjects were $n$ ot penalized in the data analysis if they did nt perform these actions.

The six NASA-TLX individual workload atings-mental, physical and temporal demand, performance, effort, and frustration - were mormalized on ascale from 0 to 100 with 0 as low workload and 100 as high workload. They were combined into an average workload rating for each subject by data run. These average normalized workload atings were then analyzed using the analysis of varianœ procedure in SPSS [14].

In the analysis of the data, significance (for both $\mathrm{p}$ and $\chi^{2}$ ) was taken at the 0.05 kvel. Also, for main-order effects, a Tukey HSD post hoc test was done [15].

\section{RESULTS}

\section{Benefits of Predictive Information}

If a subject did mthing at all, an alert nould occur during flight for the 1-, 5-, and 15-minute initial times to an dert. Subjects could affect the time to an dert for the EGT increase and forward cargo overheat faults, or they could prevent the parameter fom eaching an alert range altogether but, in all ases, they had to actively confront the failure. For $\mathrm{t}$ he initial time to an dert of ETA +45 minutes, subjects did not have to do anything since an alert would not be eached until after hnding.

Alert $\mathrm{O}$ currence: For $\mathrm{t}$ he 1-, 5-, and 15-minute initial times to $\mathrm{a}$ alert, whether or not $\mathrm{a}$ alert occurred depended on the initial time to an alert $\left(\chi^{2} \leq 0.01\right)$. Out of a possible 48 alerts, only 19 occured (table 2). As sen in table 2, the greater the initial time to an dert, the more often subjects avoided an alert. Hence, subjects were taking actions to lessen the severity of the failure, to lessen the time pressure associated with the alert, and to lessen its consequences.

Table 2 -Number of Alert Occurrences

\begin{tabular}{l|l}
\hline Alert & Initial Time to Alert (minutes) \\
\cline { 2 - 2 }
\end{tabular}




\begin{tabular}{|l|rrrcc|} 
Present & 1 & 5 & 15 & ETA+45 & Total \\
\hline \hline Yes & 10 & 8 & 1 & 0 & 19 \\
No & 2 & 4 & 11 & 12 & 29 \\
\hline
\end{tabular}

Action Before or After Alert: Since subjects had time to deal with the fiilure before an alert, whether they acted before or after an alert ocaurred was of interest. In both the direction and time conditions, subjects brought up the checklist before any alerts $\left(\chi^{2} \leq 0.02\right)$ (table 3 ). This is not suprising $b$ ecause in the direction and time conditions, subjects had foreknowledge of the alert and which checklist was pertinent. F urthermore, the number of dhecklists accessed before an alert in the baseline condition may be artificially high because subjects were primed fr a failure. Thus, they may have been more diligent in scanning the instruments boking for deviations.

Table 3 -Number of Checklists Retrieved for the 1-, 5-, and 15-Minute hitial Times to an Alert

\begin{tabular}{|l|cccc|}
\hline \multirow{2}{*}{ Before Alert } & \multicolumn{3}{|c|}{ Predictive Information } & \\
\cline { 2 - 4 } & Baseline & Direction & Time & Total \\
\hline \hline Yes & 8 & 12 & 12 & 32 \\
No & 4 & 0 & 0 & 4 \\
\hline
\end{tabular}

Predictive information was dso significant in determining whether pilots accessed checklists for the ETA+45 minute condition $\left(\chi^{2} \leq 0.02\right)$ (table 4$)$. No subjects in the baseline condition accessed a checklist but subjects did when they had direction or time information. Again, this was because they had an advisory message telling them which checklist was relevant to the failure.

Table 4 -Number of Checklists Retrieved for ETA+45 Minute Initial Time to an Alert

\begin{tabular}{|l|cccc|}
\hline \multirow{2}{*}{ Retrieved } & \multicolumn{3}{|c|}{ Predictive Information } & \\
\cline { 2 - 4 } & Baseline & Direction & Time & $\begin{array}{c}\text { Tota } \\
1\end{array}$ \\
\hline \hline Yes & 0 & 4 & 3 & 7 \\
No & 4 & 0 & 1 & 5 \\
\hline
\end{tabular}

As the nitial time to an alert increased up to the 15-minute condition, the number of subjects diverting and declaring emergencies before an dert range was reached also increased $\left(\chi^{2} \leq 0.01 \mathrm{f}\right.$ or both) (table 5). $\mathrm{S}$ ince they knew the information to be accurate, subjects decided to confront the problem before the alert; the more time they had before an alert, the more likely they would declare an emergency (in order to get preferential handling from ATC) and divert before the alert. In three cases, subjects did nt divert if the alert was going to occur during the flight. These three cases involved the cargo fire failure and the subjects discharged the forward argo fire bottle before an alert was reached. On the other hand, one subject in the ETA +45 minute direction condition did divert for the oil quantity decrease failure even though it was not required.

Table 5 -Number of Diversions and Emergencies

\begin{tabular}{|c|lll|}
\hline \multirow{2}{*}{ Before Alert } & \multicolumn{2}{|l|}{$\begin{array}{l}\text { Initial Time to an } \\
\text { Alert (minutes) }\end{array}$} \\
\cline { 2 - 3 } Total \\
\hline
\end{tabular}

\begin{tabular}{|ll|rrrr|}
\hline \hline Divert & Yes & 0 & 7 & 9 & 16 \\
& No & 11 & 4 & 2 & 17 \\
Dedare & Yes & 2 & 5 & 8 & 15 \\
Emergency & No & 8 & 3 & 1 & 12 \\
\hline
\end{tabular}

Workload: For workload, predictive information and initial time to alert were significant, $p \leq 0.04$ for both. As expected, the ETA +45 minute initial time to an dert had the 1 owest workload rating (table 6). This was because subjects did not have to confront the failure, if they even noticed the problem, since the alert was going to ocaur after landing.

Table 6 -Workload Ratings

\begin{tabular}{|c|c|c|c|}
\hline \multicolumn{2}{|c|}{ Factor } & Mean & St Dev \\
\hline Initial Time & 1 & 41 & 19 \\
\hline to Alert & 5 & 41 & 19 \\
\hline (minutes) & 15 & 41 & 9 \\
\hline & $\mathrm{ETA}+45$ & 26 & 13 \\
\hline Predictive & Baseline & 28 & 15 \\
\hline Information & Direction & 43 & 18 \\
\hline & Time & 40 & 18 \\
\hline
\end{tabular}

Note: $0=$ low workload, $100=$ high workload

For $\mathrm{p}$ redictive information, workload was rated significantly 1 ower for the baseline condition than the direction $\mathrm{c}$ ondition (table 6). The $\mathrm{b}$ aseline predictive information was familiar to the subjects since this is the information they aurrently use and this contributed to its low workload rating.

Unlike the time condition, subjects had to estimate how much time they had before an alert range would be reached for the direction predictive information. The only way to do this was to pproximate the parameter's rate of change. This appeared to increase the workload.

The greatest contributor to workload ppears to be choosing which actions to carry out. No procedures were given regarding $\mathrm{t}$ he use of direction and time predictive information and this, most likely, accounted for subjects rating workload for time predictive information closer to direction predictive $\mathrm{i}$ nformation than to the baseline condition. A pparently, deciding on the proper course of actions for the direction and time conditions increased workload more than estimating the time to an alert for the direction condition.

\section{Predictive Information Type and Prediction Times}

As mentioned earlier, subjects could take several actions during each fiilure ranging from trying to affect the onset of an alert to dverting to an altemate airfield. As expected, the predictive information available and the initial time to an alert affected when subjects initiated a particular ation during the 1-, 5-, and 15-minute initial times to an alert.

The time of dhecklist access was heavily influenced by the availability of predictive information $(\mathrm{p} \leq 0.01)$ (table 7$)$. The baseline condition was statistically hter than the drection and $t$ ime conditions. As explained above, this was not suprising since s ubjects knew which dhecklists were pertinent before the alert occurred in these two conditions.

Table 7 -Normalized Checklist Access Time (minutes) 


\begin{tabular}{|c|cc|}
\hline Predictive Information & Mean & St Dev \\
\hline \hline Baseline & 0.87 & 0.54 \\
Direction & 0.12 & 0.11 \\
Time & 0.10 & 0.16 \\
\hline
\end{tabular}

With regard to descending, dverting, checking weather, declaring an emergency, calling the flight attendant, and calling dispatch, the initial time to an alert was significant $(\mathrm{p} \leq 0.03$ for all) (table 8$)$. In all cases, the 5- and 15-minute conditions $\mathrm{w}$ ere statistically earlier than the 1-minute condition. Basically, the more time subjects had before an alert, the earlier they performed the actions relative to the time to an alert.

Table 8 -Normalized Times (minutes)

\begin{tabular}{|lc|ccc|}
\hline Action & $\begin{array}{c}\text { Initial Time } \\
\text { to an Alert }\end{array}$ & $\mathrm{N}$ & Mean & $\begin{array}{c}\text { St } \\
\text { Dev }\end{array}$ \\
\hline \hline Descend & 1 minute & 7 & 2.16 & 1.26 \\
& 5 minutes & 9 & 0.87 & 0.40 \\
Divert & 15 minutes & 9 & 0.46 & 0.34 \\
& 1 minute & 11 & 4.19 & 2.15 \\
& 5 minutes & 11 & 1.10 & 0.64 \\
Check & 15 minutes & 11 & 0.56 & 0.37 \\
Weather & 1 minute & 6 & 5.28 & 3.87 \\
& 5 minutes & 7 & 1.63 & 1.19 \\
Declare & 15 minutes & 8 & 0.55 & 0.55 \\
Emergency & 1 minute & 10 & 2.81 & 1.63 \\
& 5 minutes & 8 & 0.95 & 0.53 \\
Call Flight & 15 minutes & 9 & 0.56 & 0.35 \\
Attendant & 1 minute & 10 & 4.48 & 2.24 \\
& 5 minutes & 11 & 1.25 & 0.62 \\
Call & 15 minutes & 9 & 0.38 & 0.28 \\
Dispatch & 1 minute & 9 & 6.04 & 2.54 \\
& 5 minutes & 9 & 1.54 & 0.80 \\
& 15 minutes & 10 & 0.55 & 0.33 \\
\hline
\end{tabular}

Since the above results held for all ations, the 1-minute condition was s eparated out from the 5- and 15-minute conditions because the 1-minute œndition dd not allow for much time to prepare for the alert whereas the aher two conditions did. The analysis was then redone using the data from the 5- and 15-minute initial times to an alert

With the reanalysis for the 5- and 15-minute conditions, descent time, diversion time, and time to declare an emergency $\mathrm{w}$ ere found to be dependent on predictive information ( table 9). In a 11 cases, time predictive information $\mathrm{w}$ as significantly lower from baseline. Depending on the action, direction predictive information may or may not be different from the baseline condition or the time condition (table 9). Hence, the direction predictive information does decrease the time of when a subject performs a certain action but this decrease in time is not as differentiable from the baseline condition as is the time predictive information.

For all actions described above, the 5-minute condition had significantly 1 ater times than the 15 -minute condition. Furthermore, even though previous research suggested this, no interaction ocaurred between predictive information and initial time to an alett. In fact, time predictive information always had an earlier ation initiation time. Thus, dthough pilots reported wanting the direction type of predictive information for times $\mathbf{t o}$ an alert of 5 minutes o less, in practice, time predictive information appears also to have the greatest benefits for the 5-minute initial time $\mathrm{t}$ an alert.

Table 9 -Normalized Times for 5- and 15-Minute Initial Times to an Alert (minutes)

\begin{tabular}{|c|c|c|c|c|}
\hline Action & $\begin{array}{l}\text { Predictive } \\
\text { Information }\end{array}$ & $\mathrm{N}$ & Mean & $\begin{array}{c}\text { St } \\
\text { Dev }\end{array}$ \\
\hline \multirow[t]{3}{*}{$\overline{\text { Descend }}$} & Blaseline & 12 & 0.94 & 0.41 \\
\hline & Directi & 12 & 0.77 & 0.39 \\
\hline & Time & 12 & 0.44 & 0.33 \\
\hline \multirow[t]{3}{*}{ Divert } & aseline & 13 & 1.18 & 0.60 \\
\hline & jirection & 13 & 0.84 & 0.62 \\
\hline & Time & 14 & 0.81 & 0.25 \\
\hline Declare & Baseline & 12 & 1.04 & 0.39 \\
\hline \multirow[t]{2}{*}{ Emergency } & irection & 7 & 0.69 & 0.31 \\
\hline & me & 12 & 0.38 & 0.24 \\
\hline
\end{tabular}

In general, for a short time to an alert (1 minute), subjects did not have much time to use the advance motification. For longer times to an alert (5 and 15 minutes), subjects had time to affect the timing and ocarrence of the alert and to prepare for $t$ he alert. In fact, the time and direction predictive $\mathrm{i}$ nformation aided them in acessing the appropriate hecklist, declaring an emergency, and diverting before an alert occurred.

\section{DISCUSSION}

To identify the benefits of predictive information, $t$ determine the form of predictive information and range of prediction times, and to corroborate previous research, a simulator experiment $t$ esting three types of predictive information and four initial times to an alert was conducted. The three types of predictive information were (1) baseline, (2) direction, and (3) time, and the fur initial times to an alert were (1) 1 minute, (2) 5 minutes, (3) 15 minutes, and (4) ETA+45 minutes. These factors were found to affect when $\mathrm{s}$ ubjects accomplished certain actions, such as accessing $\mathrm{p}$ ertinent checklists, declaing emergencies, diverting, and calling the fight attendant and dispatch.

Knowing the remaining time o an alert seemed to produce the most benefits. For instance, the more time subjects had to deal with the filure, the more often they avoided getting an alert by performing some action such as descending, shutting d own the affected engine, or discharging fire bottles. The initial time to an dert also affected when subjects performed certain ations. As the initial time to an alert i ncreased, subjects were more likely to declare an emergency and to dvert before a parameter reached an alert range.

Predictive i fformation also affected when subjects were more 1 ikely 10 access the appropriate checklist. With direction or time predictive information available, they often accessed checklists before an alert ocurred.

Finally, the direction and time predictive infomation had higher workload a ssociated with it than the baseline 
information. This was most likely because subjects had to decide how to use the new information.

Regarding the prediction time, subjects diverted, checked weather, $d$ eclared an emergency, and called the fight attendant and dispatch earlier for the 5- and 15-minute initial times to an alert than for the 1-minute initial time to an alert.

Within the 5- and 15-minute initial times to an alert, descent time, $\mathrm{d}$ iversion time, and time to declare an emergency were less for the time and drection predictive information $t$ han they were for the baseline condition, although the direction condition was not always different from the baseline condition. This might have been due to the heightened a wareness of the subjects to possible failures. Also, within these two initial times to an alert, descent time, diversion time, time to check weather, time to declare an emergency, and time to all fight attendant for the 5 -minute condition were statistically more than the times for the 15-minute condition. Lastly, although pilots indicated $\mathrm{i} \mathrm{n}$ previous esearch an interaction between predictive $\mathrm{i}$ nformation and initial time to an alert, in practice, there appears to be no such interaction.

\section{CONCLUSION}

The data do suggest that predictive information may be beneficial to increasing the safety of flight although, in this experiment, the initial time to an alert more heavily affected the performance. This, most likely, was due to subjects being primed for failures, so they were more actively scanning the instruments for these failures. In any case, providing the time to an alert for the longer initial times to an alert allowed subjects to prepare fr checklists and to declare emergencies earlier in order to receive preferential handling from ATC so that they could descend and divert more easily and timely. Subjects also let ahers know of the situation e arlier, such as dispatch and the flight attendants, when they had the predictive information. But for workload to decrease to the level it arrently is with no predictive information, flight aews need to become familiar with and fully understand this information.

Other a spects must also be investigated before the full usefulness of predictive information an be understood. Further research into the optimal prediction time, acceptable false alarm ate, and accuracy of the predictive information must be done. Also, it would be of benefit to ascertain how useful the information would be when pilots are not primed for a failure. On the more operational side, the ability to estimate the time to an alert with the false alarm rate and acauracy required by the pilots reeds to be investigated before procedures are developed using the time to an alert predictive information.

\section{REFERENCES}

[1] Aircraft A ccident Report, Eastern Airlines, Inc., Lockheed L-1011, N334EA, Miami International Aiport, Miami, F lorida, May 5, 1983, NTSB-AAR-84-04, National T ransportation Safety Board, Mar. 1984. (Available from NTIS as PB84 910 404.)
[2] Batelle, Aviation Safety Reporting System, S earch Request Number 1 929, Aircraft Subsystems Failures, Mountain View, California, 1990.

[3] E.J. McCormick and M.S. Sanders, Human Factors in Engineering and Design, Fifth ed., McGraw-Hill, 1982.

[4] C.D. Widkens, Engineering Psychology and Himan Performance, Scott, Foresman \& Co., 1984.

[5] E.L. Weiner, B.G. Kanki and R.L. Helmreich, eds., Cockpit Resource Management, Academic Press, 1993.

[6] A.C. Trujillo, Effects of Historical and Predictive Information on Ability of Transport Pilot to Predict an Alert, NASA TM-4547, 1994.

[7] A.C. T rujillo, Airline Transport Pilot Preferences for Predictive Information, NASA TM-4702, 1996.

[8] 767 F light Manual - Handbook, Revision \#72, United Airlines SFOEG - New Aircraft and Operational Engineening, Oct. 1986.

[9] Correspondence with $\mathrm{R}$ ichard Gifford, UAL Pilot, Ret., 1996.

[10] Correspondence w ith Dave Simmon, UAL Pilot, Ret., 1996.

[11] T.W. Wild, Transport $C$ ategory Aircraft Systems, IAP, Inc, 1990.

[12] $757 Q$ uick Reference Handbook, T he Boeing Company, Feb. 1992.

[13] S.G. H at and L.E. Staveland, "Development of NASA-TLX (Task Load Index): Results of Empirical and Theoretical Research," In P. A. Hancodk \& N Meshkati (Eds.), Human Mental Workload, North-Holland: Elsevier, 1988.

[14] SPSS, SPSS ${ }^{\circledR} 7.5$ for Windows ${ }^{\circledR}$, SPSS hc., 1997.

[15] D.C. Howell, Statistical Methods for Psychology, $2^{\text {nd }}$ ed., Boston: Duxbury Press, 1987. 